\title{
Using Google Trends in International Tourism: A Case Study of the Czech and Slovak Republics
}

\author{
Patrik Kajzar \\ Silesian University in Opava, Czech Republic \\ kajzar@opf.slu.cz \\ Radim Dolák \\ Silesian University in Opava, Czech Republic \\ dolak@opf.slu.cz \\ Radmila Krkošková \\ Silesian University in Opava, Czech Republic \\ krkoskova@opf.slu.cz
}

This paper deals with using Google Trends in International Tourism. The attention will be focused on analysing the behaviour of Czech and Slovak tourists travelling to seaside resorts between the years 2010-2019. This paper aims to determine whether there is a connection between the data from the official statistics where Czech and Slovak tourists went and what they were searching on Google Search. The authors also compare the Google Trends analysis with the statistical data for Czech and Slovak tourists travelling to seaside resorts. The paper uses the data from 2010 related to the popularity of Czech and Slovak destinations; the data from 2019 to December is not available yet. This paper will also provide detailed statistical reports using the Spearman's rank correlation coefficient. It is very important to mention that this article focuses only on the Google Trends analysis for the travelling category. Destination selection is a complex process that is influenced by many factors. Google Trends is a useful tool for a prediction about travelling to seaside resorts, but that does not always accurately reflect the popularity of a destination compared to statistics.

Keywords: Google Trends, tourism, Czech, Slovak, seaside resorts

(cc)BY-SA https://doi.org/10.26493/2335-4194.14.205-216

\section{Introduction}

Tourism is a growing phenomenon, both in size and impact. According to Mura and Kajzar (2018), tourism is travel for pleasure or business; it is also the theory and practice of touring, the business of attracting, accommodating, and entertaining tourists, and the business of operating tours (Benevolo \& Spinelli, 2018). Small and medium-sized enterprises constitute a significant part of the Czech and Slovak economies, with the greatest potential for growth and impact on eco- nomic stabilization and balanced development of the regions (Kovalová et al., 2018).

The Internet is generally known as the primary information source for searching for information. The Internet is also the most important source for searching for information about travelling. People very often organize their travelling according to information on the Internet using Google services; this is stored in Google company databases, and we can analyse searching information in Google Trends service. 
What is the definition of Google Trends? We can mention for example the following definition: Google Trends is a tool that offers a variety of information such as the searches that are currently popular, historical data for search keywords, and traffic trends for websites searchers are interested in. Google Trends allows entry of multiple search keywords so that you can compare and contrast. It also gives search trends by limiting to a specific geographic location (Benckendorff et al., 2019). A side effect is the ability to follow trends relatively easily. In the field of internet business, monitoring and predicting trends is a very important factor that can stand between success and failure.

Google Trends is a very powerful service that allows different analyses which can be useful for some research of searching trends in tourism, services, products, etc. More information about the Google Trends service can be found in the book Google Trends: The Ultimate Step-by-Step Guide, (Blokdyk, 2018) which is characterized as a guide that ensures all Google Trends essentials are covered from every angle.

We will summarize literature sources that deal with using Google Trends in tourism in the first chapter and then we will discuss the issue of analysing the behaviour of Czech and Slovak tourists travelling to seaside resorts between 2010-2019, based on the data from Google Trends and official statistics provided by the Czech Statistical Office and the Statistical Office of the Slovak Republic.

\section{Theoretical background}

The rapid growth of digital technology and intensive presence on social media platforms leads to the emergence of online content sharing (people to people), which results in the emergence of the sharing economy (e.g. Krajcik et al., 2019; Mura \& Kajzar, 2019).

We can find some literature sources that deal with using Google Trends in tourism. The Google Trends analysis was used for forecasting tourism demand in some areas such as, for example the master thesis, Forecasting Tourism Demand in Amsterdam with Google Trends: A Research into the Forecasting Potential of Google Trends for Tourism Demand in Amsterdam (Rödel, 2017). Also interesting is a study that examines the usefulness of Google Trends data in pre- dicting monthly tourist arrivals and overnight stays in Prague during the period between January 2010 and December 2016 (Havranek \& Zeynalov, 2018).

According to Gorete et al. (2019), Google Trends has been increasingly used in research publications in tourism and hospitality, but the range of its applications and methods used has not yet been reviewed. Therefore, a systematic review of the existing literature increases awareness of its potential uses in tourism and hospitality research and facilitates and helps a better understanding of its strengths and weaknesses as a research tool. We can also find numerous research papers using statistical analysis to characterize and compare the number of visitors in some countries, districts, or towns. Kasagranda (2012) has compared the number of visitors of the Nomenclature of Units for Territorial Statistics (NU TS II) - Central Slovakia at regional and district levels in two selected years, 2001 and 2011. Another paper deals with regional disparities in Slovakia and the Czech Republic. For example, Ivanova and Koisova (2014) deal with similarities or disparities in development according to the analysed indicators in the Slovak and Czech regions in the given period 2001-2012. Time series data about the frequency of hits for tourism-related search terms from Google Trends service is used as a predictor. Another example of studies about search enginedatabased tourism demand prediction is by Park et al. (2017), which considers tourist inflow from Japan to South Korea, or by Artola and Martínez-Galán (2012), who forecast numbers of British tourists in Spain. The authors of this paper agree with Bokelmann and Lessmann (2019) that tourism demand forecasting remains an open research field since no method is generally considered most accurate.

A destination that develops a thematic product with a combination of three elements, fun, experience, and exploring, becomes fashionable. Costa et al. (2016) examine the key trends in tourism and approaches for scanning the business environment and the tourism industry. The tourism industry is one of the fastest-growing industries in the world (Ranasinghe, 2019). The focus of the article is important because the tourism industry is an entrepreneurial sector providing various kinds of services that in- 
volve providers of accommodation facilities from hotel chains to small private boarding houses, and also a sector related to tourist attractions: national parks; cultural and historical sights; theme parks; botanic gardens; sports centres; transport and the destination organization sector. A change can be observed in the number and structure of domestic and foreign tourists, and at the same time, the demand for quality services is increasing (Kubala \& Vetráková, 2018). It has been found that tourism stimulates local economies, attracts foreign investments, increases entrepreneurial activities, raises property value, develops social infrastructure, and attracts a wealthy middle class (Zeng-Xian \& Tak-Kee, 2016).

According to Walby and Piché (2015), tourism is a social, cultural, and economic phenomenon that entails the movement of people to countries or places outside their usual environment for personal or business/professional purposes. Many travellers seek escape, pleasure, friendships, relaxation, and unusual experiences (Bácsné Bába et al. 2018).

It might be well accepted nowadays that intensive competitiveness in terms of both quantity and quality makes it extremely difficult for a firm to differentiate itself from its competitors. Moreover, dynamic business environments and increasing customer power have pushed firms toward a customer-focused strategy, especially using new technology to build relationships with the customer (Minh \& Huu, 2016). In a complex and dynamic business environment, managers appeal widely to modern methods and techniques that could help them cope with the competition and offer their customers new, attractive, good quality products and services at competitive prices. In this context, total quality management is a viable and sustainable option that can systematically contribute to the consolidation of the capacity of organizations (Androniceanu, 2017). Tourism studies suggest that being a competitive destination means being able to increase the tourism sector and the quality of life of the population (Croes, 2010).

\section{Data and Methodology}

The Internet is used by millions of people daily to find different types of information. The Internet is also the most important source for searching for information about travelling. People very often organize their travel according to information on the Internet. The most common search engine is Google, accounting for $75 \%$ of these searches. Information about searching using Google services is stored in Google company databases and we can analyse this data using the Google Trends service. Google Trends is a service that can monitor the popularity of search topics and terms over a specified period (Dey et al., 2019). Google Trends provides access to a largely unfiltered sample of actual search requests made to Google. It is anonymized (no one is personally identified), categorized (determining the topic for a search query), and aggregated (grouped). This allows us to display interest in a particular topic from around the globe or down to city-level geography (Google Help, n.d.).

Google Trends (https://trends.google.com/trends/) provides a web interface for mining Google's search history database. Users may mine the database using preconstructed 'topics' or via the free-text of a given search entry. In our search, the topic 'Google Trends in tourism' was used. Google Trends data reflects searches people make on Google every day, but it can also reflect irregular search activity, such as automated searches or queries that may be associated with attempts to spam our search results. Google Trends data should always be considered as one data point among others before making conclusions. According to Rogers (2016), there are two ways to filter the Trends data: real-time and non-real-time. Real-time is a random sample of searches from the last seven days, while non-real-time is another random sample of the full Google dataset that can go back anywhere from 2004 to approximately 36 hours ago. The charts will show you either one or the other, but not both simultaneously, because these are two separate random samples. What is most useful for storytelling is normalized trends data. This means that when we look at search interest over time for a topic, we look at that interest as a proportion of all searches related to all topics on Google at a given time and location. Google Trends allows entry of multiple search keywords so that one can compare and contrast. It also gives search trends by limiting to a specific geographic location 
(Benckendorff et al., 2019). When we look at regional search interest for a topic, we look at the search interest for that topic in a given region as a proportion of all searches related to all topics on Google in that same place and time. The context of our numbers also matters. We index our data to 100 , where 100 is the maximum search interest for the time and location selected. Understanding the percent increase in a search topic can be a useful way to understand how much rise in interest there is in a topic. This percent increase is based on a topic's growth in search interest over a distinct period compared to the previous period.

We can see the important role of information and communications technology (ICT) in tourism. Cákoci (2012) deals with a short review of development and changes in tourism under the influence of information technologies. The paper describes using the internet in tourism from the beginning, over its dramatic growth, until its current main position in tourism information distribution, as a communication medium, and a place of consumption. Google services are very useful for tourism, too. We can read more information about the possibilities of using application programming interfaces from Google, in the process of a creative web page devoted to the distribution of selected information about Slovak communities in a graphically interesting presentation (Bačík, 2012).

Google Trends also allows the user to compare the volume of searches with two or more terms. An additional feature of Google Trends is its ability to show news related to the search term overlaid on the chart, showing how new events affect search popularity (Sfetcu, 2014). Google Trends allows you to size up search trends related to topics of interest broken down into geographical boundaries (states, countries, or worldwide) or thematic categories (health, science, news, and travel, among others), as well as temporal delimitations (specific periods, last five years, last week, and so forth).

The authors will first compare data from Google Trends with data from the Czech Statistical Office and the Statistical Office of the Slovak Republic. The paper also uses data from 2010 on the popularity of Czech and Slovak destinations; data from 2019 is not yet available to December 2020. The authors used differ- ent ways of presenting the data with the help of tables and graphs.

On this basis of research, two research questions have been identified:

- Is the popularity of the destinations different for Czechs and Slovaks in more than 4 cases?

- Is Google Trends data similar for searching selected keywords for Czech and Slovak internet users?

A detailed statistical report will also be provided using Spearman's rank correlation coefficient dealing with these hypotheses:

- There is a dependence on the number of visitors to the same countries in the case of stays abroad of Czech and Slovak tourists, according to official statistics.

- There is a correlation between the data from the official statistics related to the places where Czech and Slovak tourists went and what they were searching on Google Search.

We will start by comparing favourite destinations for longer trips abroad for Czechs, such as Croatia, Greece, and Bulgaria, in Figure 1.

We can see that Greece presents a much more frequent keyword for searching than Croatia. We can see changing trends in comparing interest over time between Croatia and Bulgaria because from 2017 the interest in searching for Bulgaria is much bigger than for Croatia. Although most Czechs travel to Croatia according to Table 1 , they often return to the same places, so they do not need to search for information about Croatia anymore. Croatia is a nearby resort where major problems with travelling do not exist. Holidaying in Croatia has a certain tradition in the country so one can visit with a lot of travel agencies. Holiday apartments in Croatia would be the best choice of accommodation in Croatia.

We will continue with comparing favourite destinations for Slovaks, such as Croatia, Greece, and Bulgaria in Figure 2.

We can see that Bulgaria is a more frequent keyword for searching for the Slovaks than Croatia and Greece, therefore we can conclude that there is a difference between Czech and Slovak users in terms of 


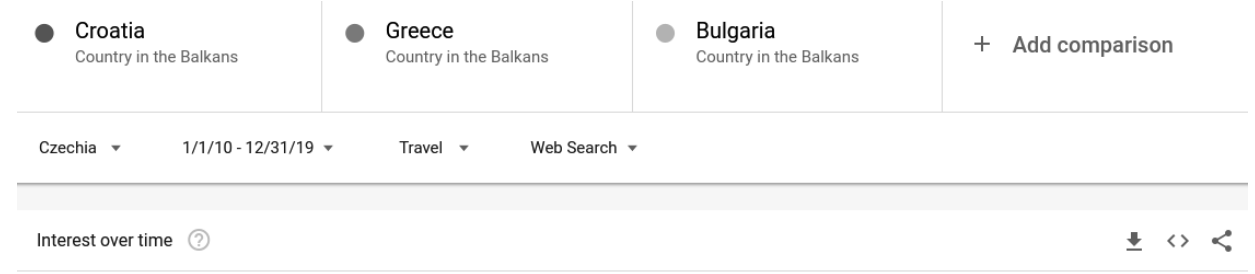

Figure 1

Google Trends

Data for Croatia,

Greece, and

Bulgaria for Czech

Internet Users

Searching

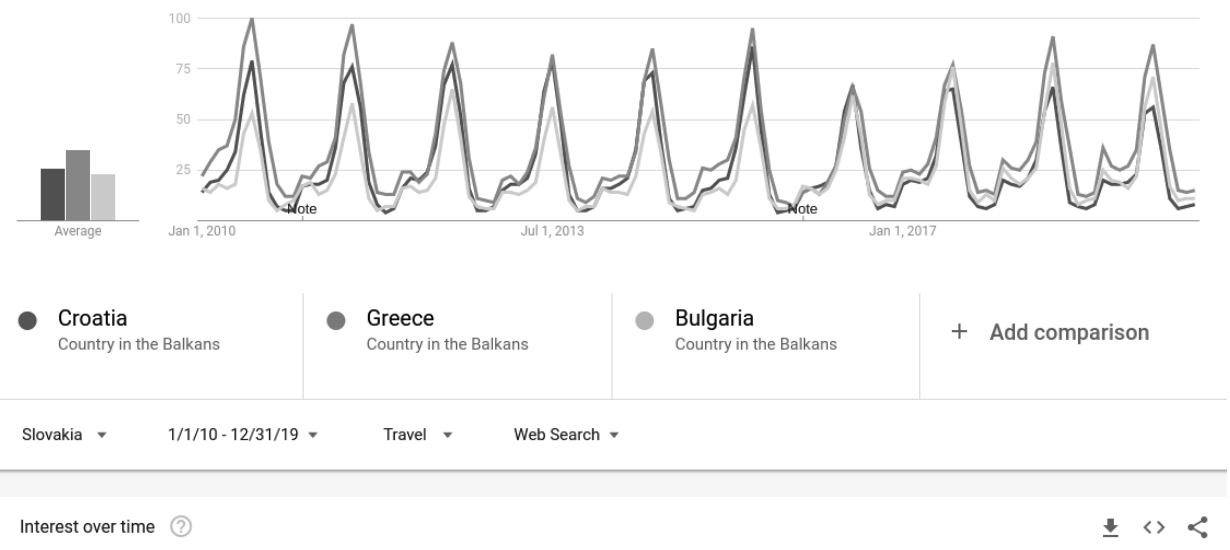

Figure 2

Google Trends

Data for Croatia,

Greece, and

Bulgaria for Slovak

Internet Users

Searching

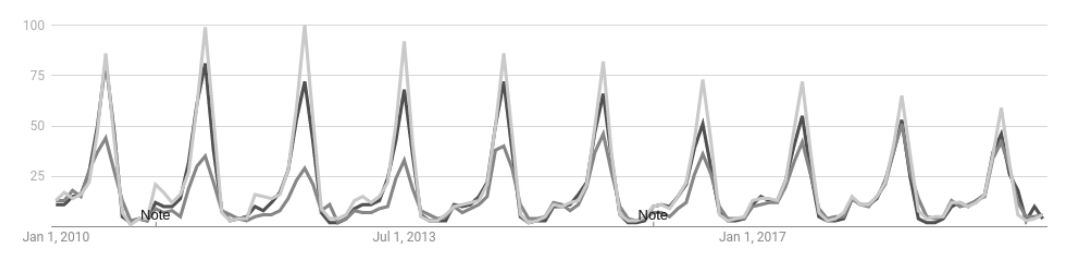

searching these countries. Bulgaria is interesting not only for the inhabitants of Western Europe but also for Slovaks, Czechs, Poles and Hungarians. Bulgaria is one of Europe's most budget-friendly destinations for cheap holidays and therefore Bulgaria holidays are often seen as a more economical alternative to the Mediterranean's best holiday destinations

We will continue with Google Trends searching for Czechs for Spain, Portugal, and Italy in Figure 3.

We can see that Italy is a more frequent keyword for searching for the Czechs than Spain and Portugal. Although Portugal is also a beautiful country, the Czechs prefer to choose a holiday to other destinations, also because of higher prices for holidays from travel agencies, unlike Italy and Greece. According to Table 1, which shows the most popular countries for longer trips abroad for Czechs, Italy has a varied tourist offer such as the sun, sea, beaches, culture, art, mountains and good food. Moreover, it is easily accessible by car, in particular the regions of northern Italy. In winter, Czech tourists enjoy holidaying in the snowy mountains of the Italian Alps, so Italy is a popular destination for Czech tourists at any time of the year.

We can see the same country interest searching for Slovak internet users in Figure 4. We can see the same Google Trends data for Spain, Portugal, and Italy for Slovak internet users searching. We can see that Italy is a much more frequent keyword for searching than Spain and Portugal. Czech users more often search for the keywords Italy and Spain than Slovak users. So we can conclude that there is a difference between Czech and Slovak users in terms of searching for these countries. Italy is one of the most popular destinations for the Slovaks for these reasons: Italian food - pizza, pasta, cheese, local fresh products, and wine, beaches, mountains, islands, lakes, and other natural wonders. 


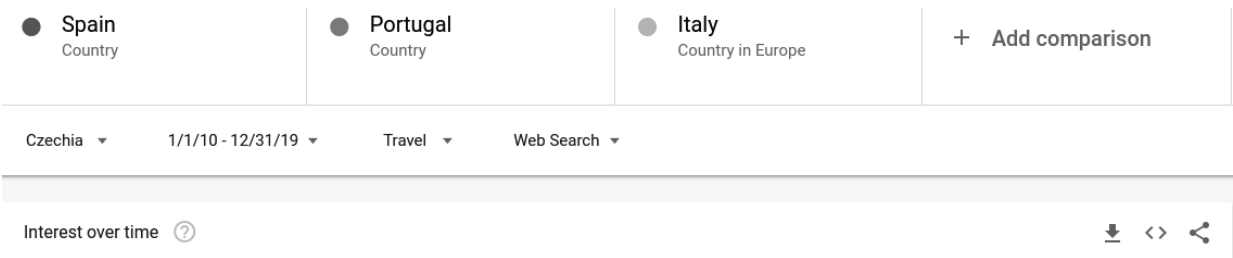

Figure 3

Google Trends

Data for Spain,

Portugal, and Italy

for Czech Internet

Users Searching

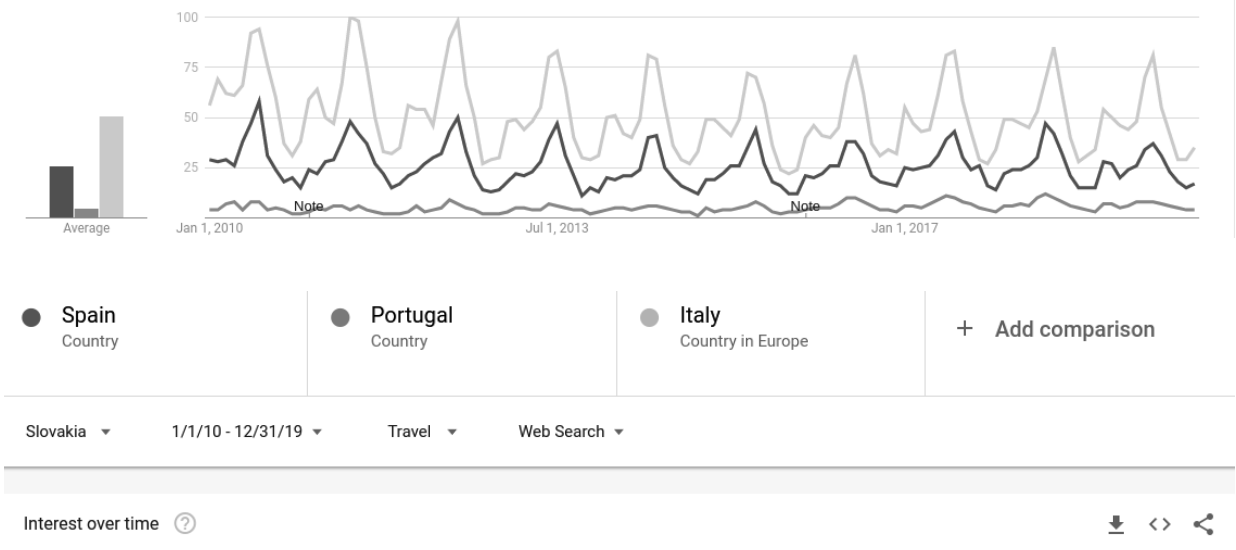

Figure 4

Google Trends

Data for Spain,

Portugal, and Italy

for Slovak Internet

Users Searching

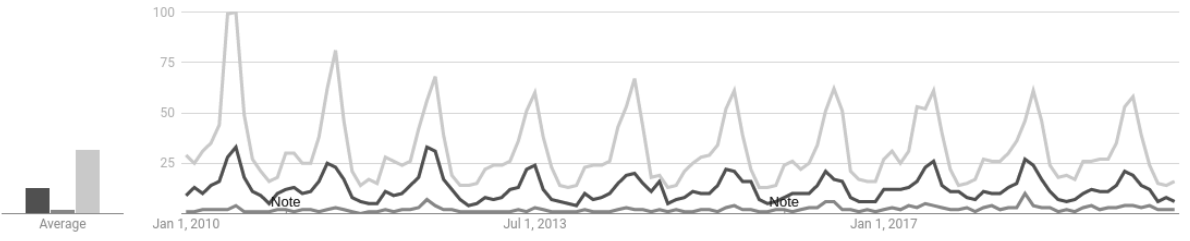

Italy is also the cradle of art and culture.

The last analysis of interest over time in searching will deal with Turkey, Egypt, and Dubai. We can see that there are minimal differences for Czech internet users searching for frequent keywords like Turkey and Egypt, followed by Dubai. We can see that Egypt, in the years 2010, 2017, and 2018, is a much more frequent keyword for searching than Turkey and Dubai. We can also see an upward trend over the past 2 years for Czech internet users searching for the keywords Turkey and Egypt. Despite the minimal differences, a bigger difference is seen in 2019 between searching for the frequent keywords Turkey and Egypt. The Czechs who go on holiday to Turkey can also expect to save significantly. In 2019, Turkey became the cheapest country out of the 11 countries that the Czechs visit most often, replacing the long-time leader Bulgaria, which is now in the second place. A Czech tourist will make a purchase in Turkey worth 57 percent higher than at home.

In Figure 6 we can see the difference for Slovak internet users searching for keywords Turkey, Egypt, and Dubai. For every year, we can see that the most frequent searching keyword is Turkey. In the year 2016, Slovak internet users searched for the keywords Turkey and Egypt least because of a military coup and terrorist attacks, respectively. In addition to Dubai, an upward trend can be seen over the past 3 years for Slovak internet users searching for the keywords Turkey and Egypt. We can conclude that there is a difference between Czech and Slovak users in terms of searching for these countries. Slovak internet users search for the keyword Turkey more often than Egypt and Dubai. Turkey is popular for Slovaks due to Turkish history and monuments, natural attractions such as sand and snow, Turkish gastronomy, Turkish bath (hammam), 


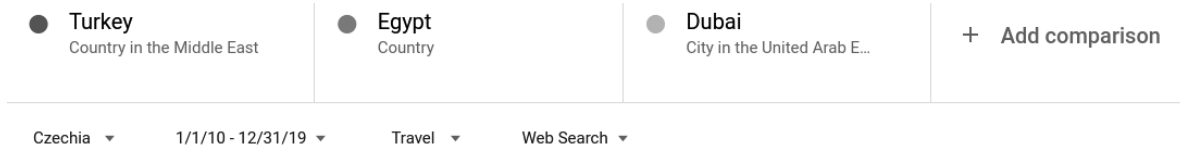

Figure 5

Google Trends

Data for Turkey,

Egypt, and Dubai

for Czech Internet

Users Searching

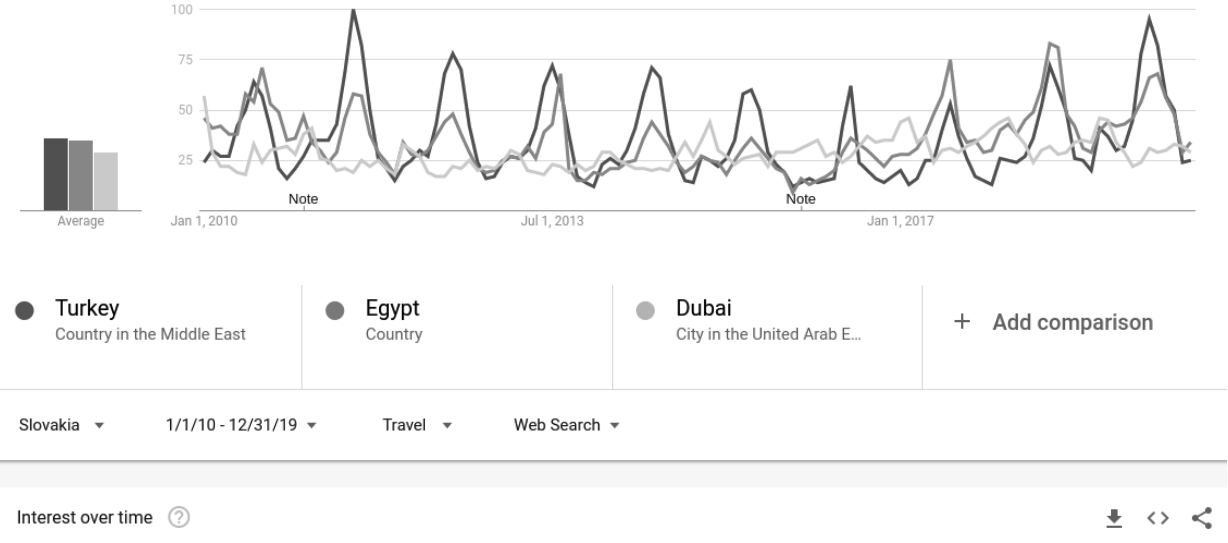

Figure 6

Google Trends

Data for Turkey,

Egypt, and Dubai

for Slovak Internet

Users Searching

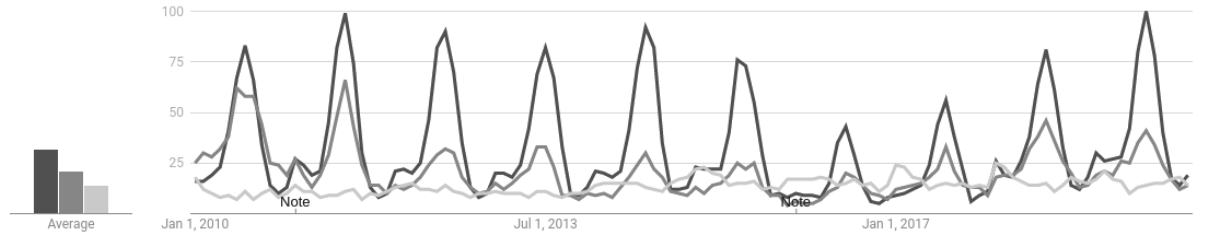

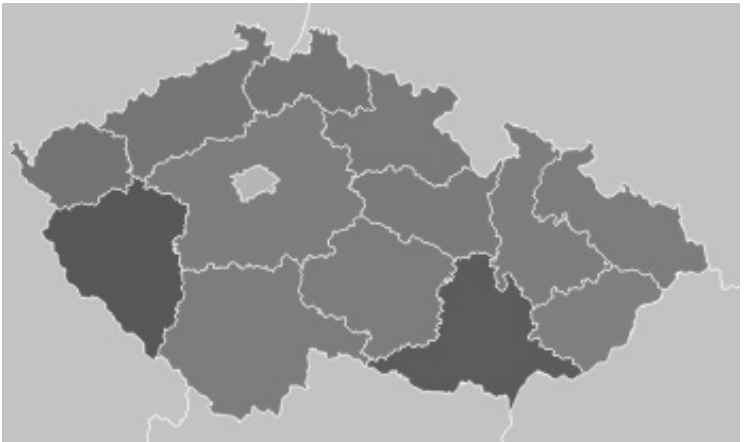

Figure 7 Google Trends Data for Turkey (dark gray), Egypt (medium gray), and Dubai (light gray) for Czech Subregions Internet Users Searching

the sea's beauty led by the Blue Lagoon, and because, compared to other holiday destinations, the ratio of price and quality of services offered makes Turkey a very attractive destination.
We can also find in Google Trends an analysis for searching compared by subregions in a specific country. According to Figure 7, we can see that the keyword Dubai is a much more frequent keyword for searching in Prague between 2010 and 2019, perhaps because Prague has the highest average salary and Dubai ranks among the more luxurious destinations where you fly from the Czech Republic, mainly in winter and spring. Tens of thousands of Czechs travel to Dubai every year. These are mainly tourists whose numbers have been increasing over the long term. This is also reflected in the establishment of four direct lines per day. The keyword Turkey is a much more frequent keyword for searching in the Pilsen and South Moravia region, and the keyword Egypt is a much more frequent keyword for searching in other regions of the Czech Republic.

In the case of Slovak internet users, no Figure 8 was inserted, because the keyword Turkey is the most fre- 
Table 1 Most Popular Countries for Longer Trips Abroad for Czechs ( 4 and More Nights) in Thousands

\begin{tabular}{lrrrrrrrrr}
\hline Country & 2010 & 2011 & 2012 & 2013 & 2014 & 2015 & 2016 & 2017 & 2018 \\
\hline Croatia & 687 & 793 & 806 & 797 & 758 & 721 & 828 & 850 & 813 \\
Slovakia & 604 & 535 & 583 & 496 & 400 & 837 & 555 & 615 & 724 \\
Italy & 593 & 563 & 549 & 526 & 553 & 497 & 552 & 636 & 607 \\
Greece & 367 & 318 & 314 & 339 & 291 & 253 & 265 & 371 & 472 \\
Austria & 237 & 261 & 279 & 339 & 306 & 281 & 372 & 446 & 328 \\
Egypt & 308 & 208 & 238 & 122 & 185 & 117 & n.a & 245 & 265 \\
Spain & 126 & 231 & 198 & 185 & 174 & 132 & 182 & 258 & 211 \\
Bulgaria & 99 & 89 & 159 & 115 & 112 & 96 & n.a & 214 & 167 \\
Hungary & 117 & 104 & 134 & 90 & 166 & 183 & n.a. & n.a. & 164 \\
Turkey & 196 & 171 & 202 & 280 & 171 & 162 & n.a. & 126 & 228 \\
Portugal & 27 & 24 & 28 & 28 & 29 & 35 & 41 & 53 & 41 \\
Dubai & n.a. & n.a. & 7 & 9 & 40 & 45 & 56 & 70 & 80 \\
\hline Notes Ban
\end{tabular}

Notes Based on data from the Czech Statistical Office (https://www.czso.cz).

quent keyword for searching in all regions of the Slovak Republic between 2010 and 2019. It is no surprise that Turkey is a popular destination for the Slovaks, and this is confirmed by Table 2. Slovak holidaymakers will also pay extra for five-star all-inclusive hotels and comfortable air travel, which is similar to Czech tourists. Turkey offers a very good selection of services and quality resorts with comfort, which some Slovaks are willing to pay for, but it still does not reach the popularity of Croatia, obviously.

\section{Evaluation of Statistical Data}

We will now compare Google Trends information with official statistics provided by the Czech Statistical Office and the Statistical Office of the Slovak Republic. We can see the most popular countries for longer trips abroad for the Czechs (4 and more nights) in Table 1.

The most popular countries for longer trips abroad for the Czechs are Croatia, Slovakia, Italy, Greece, Austria, Egypt, Spain, Bulgaria, and Hungary. The number of trips changes every year. For twenty years now, Croatia has been the most popular destination for the Czechs. Only once, in 2015, did Slovakia put Croatia in second place. The Czechs went on trips abroad in 2015 to an increased extent, despite the economic difficulties of Greece and other southern countries or the wave of migration. The growth in Slovakia's popularity in 2015 was influenced by several factors, including the reduced price of fuel, attractive offer of tourism entities and geopolitical changes in the world, which encouraged tourism to neighbouring countries, Slovakia and Germany. Italy belongs to the third most popular countries for the Czechs: around 500-60o thousand trips every year were realized. You can get to the beach in Italy by car in 8 hours. Other tourists prefer the Alps, where they are on the shores of Lake Garda, combining swimming with mountain hiking. Lovers of ancient monuments and good food will also enjoy holidays in Italy.

Why do the Czechs go to Croatia in large numbers every year? The Czechs have been fascinated with the sea and there is a long history of the Czechs travelling to Croatia, one that extends well beyond the past decade. Moreover, a lot of Croatian places are places with intense Czech 'touches.' Magical Dubrovnik was painted, among others, by the Czech impressionist Antonín Slavíček. Croatia is popular mainly due to its availability, not only in terms of distance but also in price and language. The Croatian language is close to Czech. The journey by car to Croatia takes about 8 to 12 hours; if you leave South Moravia and go to the south of the country, then you can reach your 
Table 2 Most Popular Countries for Longer Trips Abroad for Slovaks (4 and More Nights) in Thousands

\begin{tabular}{|c|c|c|c|c|c|c|c|c|c|}
\hline Country & 2010 & 2011 & 2012 & 2013 & 2014 & 2015 & 2016 & 2017 & 2018 \\
\hline Czechia & 209 & 142 & 142 & 162 & 183 & 255 & 189 & 289 & 476 \\
\hline Croatia & 484 & 499 & 387 & 500 & 376 & 401 & 475 & 387 & 418 \\
\hline Italy & 197 & 187 & 186 & 227 & 79 & 207 & 225 & 236 & 220 \\
\hline Turkey & 88 & 146 & 155 & 86 & 96 & 101 & 49 & 62 & 158 \\
\hline Austria & 69 & 75 & 103 & 101 & 45 & 94 & 89 & 77 & 136 \\
\hline Bulgaria & 171 & 112 & 65 & 71 & 58 & 161 & 159 & 128 & 130 \\
\hline Hungary & 105 & 96 & 121 & 63 & n.a. & n.a. & 81 & 65 & 112 \\
\hline Greece & 132 & 79 & 83 & 64 & 71 & 100 & 75 & 87 & 92 \\
\hline Spain & 53 & 108 & 93 & - & 39 & - & 62 & 120 & 91 \\
\hline Portugal & 3 & 3 & 3 & 4 & 4 & 4 & 5 & 6 & 7 \\
\hline Egypt & 81 & 61 & 45 & 33 & 38 & 43 & 25 & 53 & 76 \\
\hline Dubai & - & - & 1 & 2 & 4 & - & - & 9 & 10 \\
\hline
\end{tabular}

Notes Based on data from the Statistical Office of the Slovak Republic (https://slovak.statistics.sk).

destination in 6 hours. Also, bus trips to Croatia are organized in large numbers. Whereas in the past the Czechs went to Croatia only for swimming in the sea and sunbathing, today they are also exploring. Every guide to Croatia recommends visiting not only the popular city of Split but also the largest city on the Istrian peninsula, Pula, the historic city of Trogir, etc.

According to a survey by the University of Rijeka in 2018, the Czechs spend an average of 390 kunas a day in Croatia, which is not much compared to the British who spend an average of 915 kunas (Rogulj, 2019).

Now we will compare data from Google Trends with data from the Statistical Office of the Slovak Republic. From the perspective of Slovaks, we can say that the most popular countries for longer trips abroad are similar to those for the Czechs, except Turkey. Croatia remains a top holiday destination for Slovak tourists; only in 2018 did Slovak tourists visit the Czech Republic more. The same situation is related to the third place of Italy, likewise a popular destination for Slovaks. Greece is far less popular from the perspective of Slovak tourists. The difference is more than 370 thousand longer trips in favour of Czech tourists. Compared to the Czechs, the Slovaks are even more conservative in the way they spend their holidays while the Czechs, although relatively slowly, are also beginning to lean towards the concept of sports holidays, Slovaks strongly prefer a relaxing style of holiday. The Czech Republic will remain the most visited neighbouring country for the Slovaks. The common past and language closeness still attract many Slovaks to holiday here.

We can see the most popular countries for longer trips abroad for the Slovaks ( 4 and more nights) in Table 2.

\section{Comparing Data Using Spearman's Rank Correlation}

We have used Spearman's rank correlation coefficient dealing with the first hypothesis: There is a dependence on the number of visitors to the same countries in the case of stays abroad of Czech and Slovak tourists according to official statistics. Spearman correlation coefficient corr $(x, y)=0.46666667$ with the null correlation null hypothesis: $t(8)=1.49241$, with a two-sided $p$-value of 0.1739 . The result is that Ho cannot be rejected at a significance level of 0.05 , so the order in travelling to the same countries for the Czech and Slovak tourists is different.

The second hypothesis was that there is a correlation between data from official statistics where Czech and Slovak tourists went and what they were searching 
on Google Search. We will start with Czech tourists: corr $(x, y)=-0.00909091$ with the null correlation null hypothesis: $t(9)=-0.0272739$, with a $p$-value of 0.9788 on both sides. Based on these findings Ho cannot be rejected at a significance level of 0.05 and there was no evidence of dependence between where they went and what they were looking for.

We will continue with Slovak tourists: corr $(x, y)$ $=0.18181818$ with the null correlation null hypothesis: $t(10)=0.584705$, with a $p$-value of 0.5717 on both sides, so the conclusion is the same as for the Czech Republic: there was no evidence of dependence between where they went and what they were looking for.

In this paper, two research questions were identified. According to the first research question, 'Is the popularity of the destinations different for Czechs and Slovaks in more than 4 cases?' we can state that the choice of the most popular countries for longer trips abroad for the Czechs and the Slovaks differs only in one case, and that is in Egypt and Turkey, respectively. Based on the research, we can conclude that the popularity of the destinations is similar for the Czechs and the Slovaks. As far as the second research question, 'Is Google Trends data similar for searching selected keywords for Czech and Slovak internet users?' we can state that Google Trends data is different for selected keywords for Czech and Slovak internet users. For example, from the point of view of the Czechs, the keyword Greece is more frequent in searches than Croatia and Bulgaria. For the Slovaks, the keyword Bulgaria is more frequent in searches than Croatia and Greece. On the other hand, the keyword Italy is more frequent than Spain and Portugal in searches for the Czechs and the Slovaks.

In this paper two hypotheses were also stated. The first hypothesis was there was a dependence on the number of visitors to the same countries in the case of stays abroad of Czech and Slovak tourists according to official statistics. Ho cannot be rejected at a significance level of 0.05 , so the order in travelling to the same countries for the Czech and Slovak tourists is different. The second hypothesis was that there is a correlation between data from official statistics where Czech and Slovak tourists went and what they were searching on Google Search. но cannot be rejected at a significance level of 0.05 and there was no evidence of dependence between where they went and what they were looking for.

Why are search results different compared to the real behaviour of the population when selecting a destination for the holiday? The answer to these questions is not simple and of course varies from person to person. However, as travel is becoming an increasing phenomenon in our society, it does not leave psychologists and sociologists cold, either. It affects many factors: Papatheodorou (2006) says that destination choice has always been an important aspect in tourism literature and there are various factors influencing travel decisions. According to Venkatesh (2006), the factors constitute culture, travel motivations, finances, and previous experience. Travel motivations form an integral part of travel behaviour and have been widely researched and applied in tourism marketing strategies. George (2004) writes that it is not easy to understand and have adequate knowledge about the motivations affecting the travel behaviour of tourists. In a very inspiring way, he describes the motivation of travel in the work of the French author A. de Botton, The Art of Travel (2010), where he reflects on the fact that travel as an active activity hides philosophical problems, i.e. questions about why and how we should travel, to what extent travel changes us, and so on.

\section{Conclusion}

This article is devoted to the research of using Google Trends in International Tourism. Attention has been focused on analysing the behaviour of Czech and Slovak tourists travelling to seaside resorts between 2010-2019. The purpose of this article was also to compare the analysis of Google Trends with statistical data about the travel of Czech and Slovak tourists to the seaside resorts. The main aim of the research described in the paper was to find some relations between statistical data and data from Google Trends.

Google Trends has a big advantage because we can find some trends in searching or planning some tourist holidays in the actual period, but we need to wait more months to find statistics that are published by official statistical offices in the Czech or Slovak Republics. Based on the research from official statistics, 
we can conclude that the popularity of the destinations is similar for the Czechs and the Slovaks. What is the situation in searching selected keywords by the Google search engine for Czech and Slovak internet users? We have found that Google Trends data is different for selected keywords for Czech and Slovak internet users. Google Trends is a useful tool that does not always accurately reflect the popularity of a destination compared to statistics. For example, from the perspective of the Czechs, Croatia is a top destination, but Greece has surpassed Croatia in the most frequent keyword for searching for Czechs. A similar situation is found with the Slovaks. On the other hand, Google Trends corresponds to statistics for destinations in Italy, Spain, and Portugal.

We have used Spearman's rank correlation coefficient in dealing with the hypotheses: there is a dependence on the number of visitors to the same countries in the case of stays abroad of Czech and Slovak tourists according to official statistics. The priority in travelling to the same countries for the Czech and Slovak tourists is different. The second hypothesis was that there was a correlation between data from official statistics where Czech and Slovak tourists went and what they were searching on Google Search. There was no evidence of dependence between where they went and what they were looking for.

Why are search results different compared to the real behaviour of the population when selecting a destination for the holiday? Destination selection is a complex process that is influenced by many factors. When choosing a destination, we are increasingly influenced by the safety aspect of the destination, and also by the neighbourhood effect. In 2015, for example, Slovakia became the most popular destination for Czech tourists. The choice of tourist destination also affects the image of the destination. The importance of the destination image can be seen in the possibility of influence on the decision-making process of the potential visitor and subsequent consumer behaviour (experience, evaluation, satisfaction, loyalty). The criteria that affect the choice of destination can also include a tradition of destination. (One hundred years ago, Czech tourists were frequent guests in Croatian resorts. They built several hotels themselves and en- thusiastically recommended holiday trips to the Adriatic). Along with the quality of the service, the price is the basic factor influencing the client's choice. For destination management, which needs to attract the customer to its place of work, ideally repeatedly, and keep it for as long as possible, it is also necessary to know the customer's needs, as well as the process of choosing a destination.

Some potential directions of future research in using Google Trends in tourism might include among others the following topics: using Google Trends of tourists from the Visegrad Group-comparative analysis, and Google Trends analysis of searching information about Prague top visiting places between 20152019.

\section{Acknowledgments}

This paper was supported by the Ministry of Education, Youth, and Sports within the institutional support of the long-term conceptual development of a research organization in 2021.

\section{References}

Androniceanu, A. (2017). The three-dimensional approach of Total Quality Management, an essential strategic option for business excellence. Amfiteatru Economic, 19(44), $61-78$.

Artola, C., \& Martínez-Galán, E. (2012). Tracking the future on the web: Construction of leading indicators using internet searches (Banco de Espana Occasional Paper 1203). Banco de Espana.

Bácsne Bába, Ě., Müller, A., Molnár, A., Dobay, B., Bács, Z., \& Pető, K. (2018). Tourism-volunteering and sportconnections and implications from the research. Acta Oeconomica Universitatis Selye, 7(2), 19-32.

Bačík, V. (2012). Google A P a ich využitie pri tvorbe internetovej stránky obcí Slovenskej republiky. Geographia Cassoviensis, 6(1), 11-15.

Benckendorff, P. J., Xiang, Z., \& Sheldon, P. J. (2019). Tourism information technology (3rd ed.). С А В I.

Benevolo, C., \& Spinelli, R. (2018). The quality of web communication by Italian tourist ports. Tourism: An International Interdisciplinary Journal, 66(1), 52-62.

Bokelmann, B., \& Lessmann, S. (2019) Spurious patterns in Google Trends data - An analysis of the effects on tourism demand forecasting in Germany. Tourism Management, 75, 1-12. 
Blokdyk, G. (2018). Google Trends: The ultimate step-by-step guide. Create Space Independent Publishing Platform.

Cákoci, R. (2012). Vplyv internetovej služby World Wide Web na vývoj a rozvoj cestovného ruchu. Geographia Cassoviensis, 6(1), 11-15.

Costa, J., Montenegro, M., \& Gomes, J. (2016). Global trends challenging tourism organizations and destinations today: What are the likely solutions? Worldwide Hospitality and Tourism Themes, 8(6), 716-719.

Croes, R. (2010). Measuring and explaining competitiveness in the context of small island destinations. Journal of Travel Research, 5o(4), 431-442.

de Botton, A. (2010). Art of travel. Kniha Zlín.

Dey, M., Sizheng, S. Z., \& Goodson, N. (2019). Global public interest in infectious and noninfectious arthritis: An evaluation using Google Trends. Rheumatology, 59(1), 245-246.

George, R. (2004). Marketing South African tourism and hospitality. Oxford University Press.

Google Help. (N.d.). FAQ about Google Trends data. https:// support.google.com/trends/answer/4365533?hl=en

Gorete, D., Breda, Z., \& Costa, C. (2019). Google Trends in tourism and hospitality research: A systematic literature review. Journal of Hospitality and Tourism Technology, $10(4), 747-763$.

Havranek, T., \& Zeynalov, A. (2018). Forecasting tourist arrivals with Google Trends and mixed frequency data. $\mathrm{zBW}$ - Leibniz Information Centre for Economics.

Ivanova, E., \& Koisova. E. (2014). Interregional disparities in the Slovak and Czech Republic. In International Multidisciplinary Scientific Conference on Social Sciences and Arts Conference proceedings (pp. 405-412). sGEM.

Kasagranda, A. (2012). Zhodnotenie návštevnosti regiónu NU TS II - Stredné Slovensko v rokoch 2001 a 2011. Geographia Cassoviensis, 6(2), 48-56.

Kovalová, M., Hvolková, L., Klement, L., \& Klementová, V. (2018). Innovation strategies in the Slovak enterprises. Acta Oeconomica Universitatis Selye, 7(1), 79-89.

Krajcik, V., Kljucnikov, A., \& Rihova, E. (2019). Innovative sharing economy's business models in tourism: Case of Airbnb in Prague. Marketing and Management of Innovations, 2, 108-117.

Kubala, J., \& Vetráková, M. (2018). Reasons of the employees' stabilization in hotels in Slovakia. Acta Oeconomica Universitatis Selye, 7(1), 90-100.
Minh, N. V., \& Huu, N. H. (2016). The relationship between service quality, customer satisfaction, and customer loyalty: An investigation in the Vietnamese retail banking sector. Journal of Competitiveness, 8(2), 103-116.

Mura, L., \& Kajzar, P. (2018). Entrepreneurship in tourism sector in Central European country: Hospitality trends in the Czech Republic in 2007-2016. Journal of Environmental Management and Tourism, 6(30), 1351-1360.

Mura, L. \& Kajzar, P. (2019). Small businesses in cultural tourism in a Central European country. Journal of Tourism and Services, 10(19), 40-54.

Papatheodorou, A. (2006). Managing tourism destinations. Edward Elgar Publishers.

Park, S., Lee, J., \& Song, W. (2017). Short-term forecasting of Japanese tourist inflow to South Korea using google trends data. Journal of Travel \& Tourism Marketing, 34(3), 357-368.

Ranasinghe, R. (2019). Antecedents of job performance of tourism graduates: Evidence from state universitygraduated employees in Sri Lanka. Journal of Tourism and Services, 10(18), 16-34.

Rogers, S. (2016). What is Google Trends data - And what does it mean? Google News Lab. https://medium.com

/google-news-lab/what-is-google-trends-data-and-what -does-it-mean-b48fo7342ee8

Rogulj, D. (2019, September 1). Czech tourists more important for tourism in Croatia than Croatians think. Total Croatia News. https://www.total-croatia-news.com/travel/38183 -croatia

Rödel, E. (2017). Forecasting tourism demand in Amsterdam with Google Trends: A research into the forecasting potential of Google Trends for tourism demand in Amsterdam [Unpublished master thesis]. University of Twente.

Sfetcu, N. (2014). Google products, services, and tools. Selfpublished.

Venkatesh, U. (2006), Leisure: Meaning and impact on leisure travel behaviour. Journal of Services Research, 6(1), 87-108.

Walby, K., \& Piché, J. (2015). Staged authenticity in penal history sites across Canada. Tourist Studies, 5(3), 231-247.

Zeng-Xian, L., \& Tak-Kee, H. (2016). Residents' quality of life and attitudes toward tourism development in China. Journal of Tourism Management, 57(7), 56-67. 